\title{
Conceptual framework for off-site roof stacking construction
}

\author{
Mohamed Amer ${ }^{\mathrm{a}, *}$, Ahmed Mustafa ${ }^{\mathrm{b}, \mathrm{c}}$, Shady Attia ${ }^{\mathrm{a}}$ \\ ${ }^{a}$ Sustainable Buildings Design (SBD) Lab, Faculty of Applied Sciences, University of Liège, Belgium \\ ${ }^{\mathrm{b}}$ Local Environment Management and Analysis Lab, Faculty of Applied Sciences, Université de Liège, Belgium \\ ${ }^{\mathrm{c}}$ Urban System Lab, The New School, USA
}

\section{A R T I C L E I N F O}

\section{Keywords:}

Prefabrication

Modular construction

Lightweight construction

Decision making

Urban densification

\begin{abstract}
A B S T R A C T
A great deal of interest in off-site construction has been remarkable over the last decade. However, building on the rooftops of existing building has not been given a significant importance as a subject of research, despite its dependence on off-site construction and prefabrication. Thus, this paper develops a novel conceptual framework to support a multidisciplinary decision making for selecting off-site prefabricated constructional system for roof stacking. The multidisciplinary approach includes each of safety, logistics, cost, time, environmental impact, and quality of construction as major criteria in the decision making process. This paper is the outcome of an exhaustive investigation of more than 136 roof stacking projects built during the last 20 years. The development of framework is supported by a feedback validation loop based on semi-structured interviews with experts in the field of roof stacking and off-site construction.
\end{abstract}

\section{Introduction}

Conventional on-site construction "stick built" methods are being abandoned by building engineers due to the associated long construction time, higher risk records, lower productivity and vulnerability to outdoor weather conditions [1,2]. Instead, off-site construction methods have shown superior strength in shortening construction time while providing higher safety records and overall quality [3,4]. Accordingly, off-site construction took a great deal of interest in the last decades by building engineers worldwide. This interest is reflected by the exponential number of off-site construction-based projects worldwide and the conducted studies in the same field of research that aims to evaluate prefabrication methods' impact within the building industry and on environment [5-7]. Those studies were extended to include the development of tools and decision support frameworks to optimize the modular configurations and the selection of cranes, building materials and connections $[8,9]$.

Despite the numerous studies conducted in this field, there is a significant lack of integrating off-site construction and prefabrication research with roof stacking. Given that roof stacking practices are highly based on off-site construction methods and prefabrication on its multiple levels, it has not been given any importance by researchers in the field of building engineering. Building on the rooftops of existing facilities is put forward by the United Nations (UN) agendas as a sustainable approach towards achieving compact cities [10]. However, studies on roof stacking, such as that by Lawson et al. [11], Floerke et al. [12], Tichelmann and Gro $\beta$ [13], were rather general and descriptive. Despite the added value of their studies, their work remain manuals, representing qualitative reviews and lacking scientific validation. After an exhaustive review in the field of building engineering in construction, two fundamental issues have been found that lead to this shortfall, which are addressed in this paper: (i) the lack of appropriate identification and classification of the existing off-site construction methods and building materials that are specifically used for roof stacking. (ii) The lack of a definitive framework on which building engineers use to select the method of roof stacking construction.

Therefore, this paper develops a novel framework to support a multidisciplinary decision making for selecting off-site constructional system for roof stacking. A structured quantitative method has been adopted to generate a comprehensive framework that integrates roof stacking research and off-site construction practical knowledge. The framework in this paper is accomplished by developing a new classification for contemporary roof stacking construction methods. Our research approach is distinguished by: (i) adopting a multi-disciplinary approach that includes each of safety, logistics, cost, time, on-site impact, and quality of construction. (ii) Embracing a scientific validation approach for the developed framework by case studies applications from representative experts in the field of off-site construction. Given that early decision making affects $80 \%$ of the construction project's onsite activities [14,15], the outcomes of this research are aimed to

\footnotetext{
* Corresponding author.

E-mail addresses: mohamed.amer@uliege.be (M. Amer), a.mustafa@uliege.be (A. Mustafa), shady.attia@uliege.be (S. Attia).
} 
overcome the reluctance and lack of experience among building engineers to adopt prefabrication by achieving higher ascertain decision [16].

\section{Literature review and classification}

\subsection{Background}

Off-site construction adoption by the building industry returns back to early 1990's, when large number of residential buildings have been constructed using this building system worldwide [17-19]. Since then, a wide number of research were conducted to develop and evaluate offsite construction and prefabrication methods' impact on the building industry and environment. Jaillon and Poon [20] conducted examination on the sustainable aspects when adopting prefabrication in construction, in which each of the economic, environmental and social aspects have been assessed. The same researchers followed their findings with intensive review of literature and case studies to identify the benefits and drawbacks of flexible and demountable building systems including prefabrication in buildings [7]. The research of Baldwin et al. [21] focused on the evaluation of the prefabricated and precast design solution when it comes to waste reduction in residential buildings construction using modelling information flows in the design process. Lawson et al. [22] reviewed the technologies used in modular construction in Europe, showing the application of cellular approach in modular construction on a wide range of building's height and form. Other research had the interest on developing decision making criteria and indicators for nearly optimum selection of prefabricated construction method. Chen et al. [23,24] identified sustainable performance criteria on which the selection of construction methods take place. Moreover, a tool has been developed based on the identified criteria to assist building engineers to evaluate the feasibility of prefabrication during the early design stages and exploring optimal construction measures. Akadiri et al. [25] proposed a model based on fuzzy extended analytical hierarchy process for optimum building material selection, providing solutions based on sustainability principles and prioritization. Ceniceros et al. [26] developed a sustainable decision support model for selecting optimized design parameters for prefabricated floor slabs. Similar research made by Jensen et al. [27] aimed to demonstrate $\mathrm{CAD}$ tools as a mean to create design automation alternatives for modularized building systems, whereas Yuan et al. [28] combined parametric design of Building Information modelling (BIM) with Design for Manufacture and Assembly (DFMA) as a mean to overcome the unsuitability of design systems, which have been developed for nonprefabricated buildings, on prefabricated buildings. Another research by Said et al. [29] presents a platform optimization model for panelised wall systems. This platform optimizes the trade-offs between fabrication cost and minimization of design deviations. Salama et al. [30] developed sustainability indicators using five indices to formulate a modular suitability index (MSI) that aid the selection of near optimum module configuration. Sharafi et al. [31,32] developed an effective and automated method based on a unified matrix that aids the selection of compromised spatial design specifically for multi-storey modular buildings.

\subsection{Research on roof stacking}

Even though roof stacking is increasingly taking place worldwide with high potential in major European cities [33,34], very few literature was found that studied this phenomenon. There have been a couple of attempts to classify roof stacking in terms of approach, shape or structural capacity. Foelker et al. [12] gathered a large number of roof stacking projects around the world in one catalogue. The catalogue classifies the projects based on the shape of the added stories to end up in five shapes: saddle shaped roof, cubic form aligning roof surface, set back extension, free form or cantilevered, combined extension with the main building volume, and lastly juxtaposed extension to the main building. Tichelmann and Gro $\beta$ [13] made another classification based on projects built Germany. The developed classification is based on the constructive characteristics, number of added stories and the percentage of roof space occupation. Four main categories were identified: one added saddle shaped roof, one added flat roof floor, two added floors, and lastly three and more added floors. Other research recommends roof stacking as an approach towards increasing urban density showing several advantages in balancing between densification and urban landscape preservation [35]. Moreover, roof stacking showed a superior strength in decreasing energy consumption compared to only roof renovation. Marique and Reiter [36] found that roof stacking reduces the total energy consumption by $30 \%$ more than flat roof renovation when applied on an urban scale.

\subsection{Roof stacking framework development and validation method}

To develop a meaningful conceptual framework for roof stacking construction, an extensive review of literature has been conducted comprising over 40 publications in the field of building engineering, prefabrication, modularity and off-site construction. The review has extended to include decision making tools development. The aim was to overcome the shortage in literature in the field of roof stacking by collecting and reviewing articles in same related areas, exploring factors which may have an impact on roof stacking construction methods selection.

Afterwards, a wide investigation has been carried out on more than 137 roof stacking projects constructed during the last 20 years around Europe. This investigation aims to identify the contemporary construction methods used in roof stacking projects. A classification has been illustrated for each of the load bearing and assembly methods, on which the framework has been developed.

According to the established classification and identified construction method criteria of selection, a framework has been developed based on multi-disciplinary attributes, which counts for safety (S) represented by the existing building's strength and weight of the added modules, logistics (L) represented by the existing urban context and dimensional constrains, cost (C) represented by the cost of building materials and transportation, time $(\mathrm{T})$ represented by the time required to accomplish the construction off and on-site, Environmental impact (E), and quality of construction (Q).

The framework has been divided into two sequential phases. The first phase is concerned with examining the strength of the existing building and its capacity to hold additional weight. A feasibility study is conducted by the end of this first phase to determine the applicability to build on the rooftop. The second phase is concerned with the decision making on the prefabrication assembly method. Three methods have been defined based on six criteria, on which the decision making process takes place. The framework has been refined and validated by reviewing the application of several case studies that represent different methods of roof stacking. The validation process is based on reverse engineering concepts, in which semi-structured interviews have been conducted with building engineers with expertise in off-site construction and roof stacking. Each project has been analysed and broken down into 6 aspects corresponds to the predefined 6 criteria of construction methods selection. Lastly, this research reports the challenges and opportunities in the application of each construction method.

\section{Research methods}

In this section, we present the paper methodology. Similar to the work of Chen et al. [23], Salama et a. [30], Wang et al. [37] our methodology combines mixed research methods that involves quantitative (e.g. case studies), and qualitative (e.g. interviews) approaches. Qualitative data analysis in this research is characterized by being thematic, represented by the investigated case study with a descriptive 


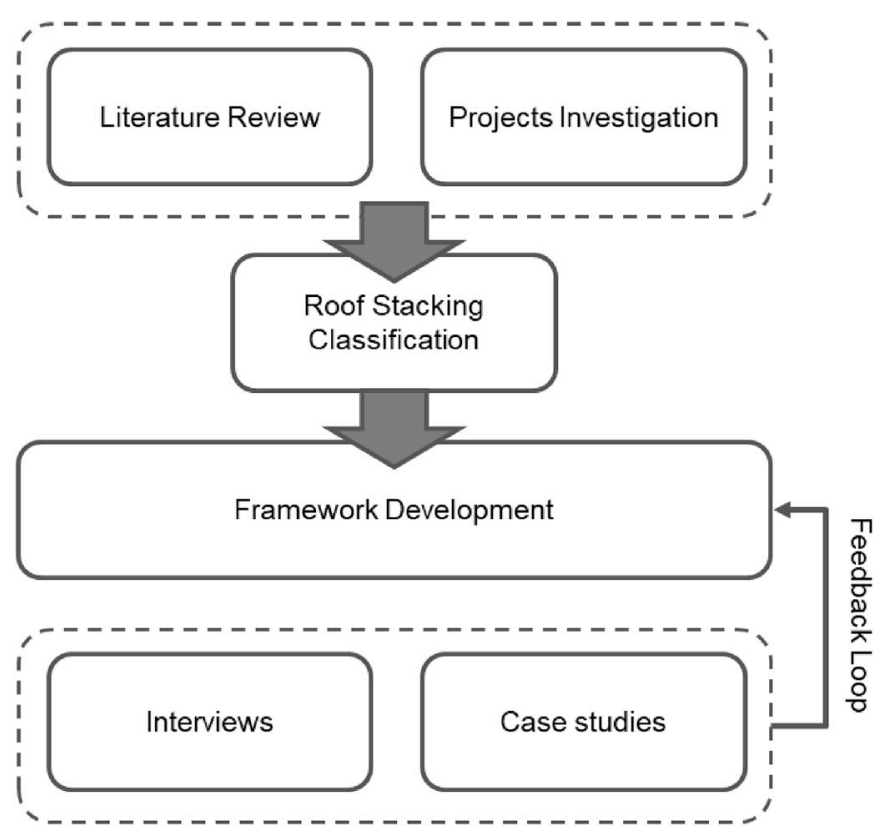

Fig. 1. Conceptual study framework.

focus. Moreover, this research strongly relies on an in-depth and intimate understanding of individual case studies. While quantitative analysis is based on filed research and statistical inference of the roof stacking case studies around Europe. The aim is to develop a novel framework to support a multidisciplinary decision making for selecting nearly optimum off-site prefabricated construction system for roof stacking. Fig. 1 illustrates a detailed workflow chart of the research methodology presented in this article.

\section{Projects review and classification}

Over 136 roof stacking projects during the last 20 years around Europe have been gathered and further analysed. Those projects were selected from different resources according to 3 different criteria. First, projects should have residential function, such as homes and apartments for single families, or hotels that accommodate temporary visitors. Second, the geographical context, by which all projects are built within urbanized European area. This criteria is made to ensure analysing the challenges concerned with urban context on roof stacking. Third, a project should not exceed 3 additional stories. These criteria ensures adequate coherence when analysing the methods and techniques used in roof stacking.

Roof stacking construction methods classification has been done under three sections: (1) classification based on load bearing methods, (2) assembly methods, and (3) building materials. As shown in Fig. 2, the classification is illustrated in two dimensional axes. The vertical axis shows the classification based on the sort of construction, while the horizontal axis is the classification based on the scale of construction.

\subsection{Roof stacking load bearing methods}

Load bearing is meant to describe the way on which the loads of the new extension is transferred to the existing building. The structural configuration, strength of the existing building, and soil allowable bearing capacity play an important in defining the options on which the loads of the added stories could be distributed. However, as a prerequisite, extra weights including water tanks, roof cover, cornices, and storages over the rooftop has to be calculated and removed to be compensated with the expected weight of the added stories.

After analysing over 136 different projects, we found two main methods of load bearing for roof stacking as shown in Fig. 2. The first

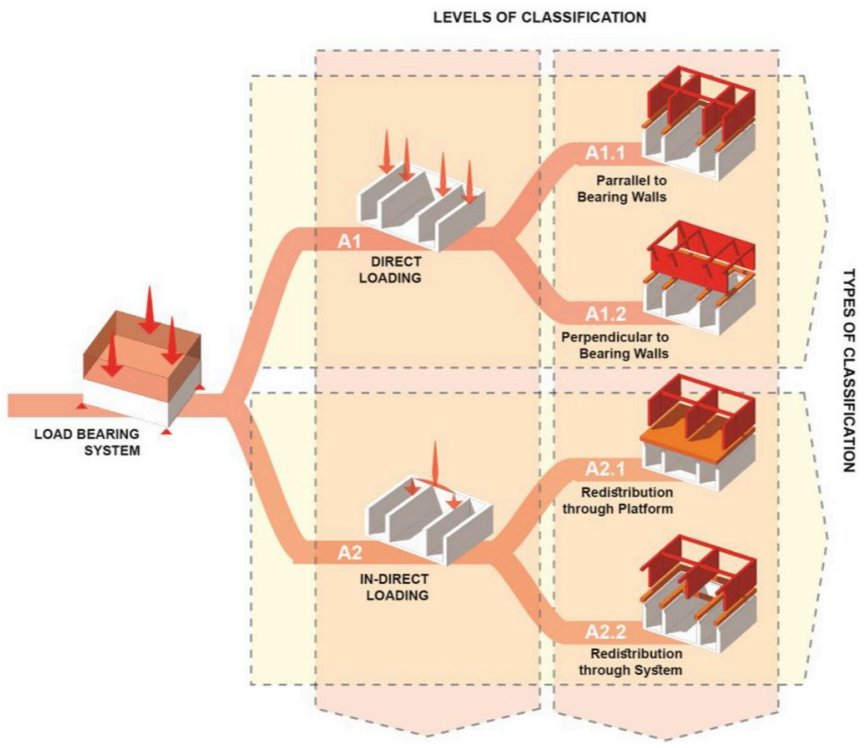

Fig. 2. Classification of roof stacking case studies based on their bearing methods.

method is through direct load bearing on the structure of the existing building. The second method is through external load bearing through additional reinforcement.

\subsubsection{Direct load bearing on walls}

This type of bearing counts on the massive walls of the outer shell of the buildings and exploits it by distributing dead and live loads on building's internal bearing walls and the envelope. This technique suits cases that take place on good state old buildings that returns back to the nineteenth and early twentieth century. Those buildings are characterized by using massive walls as a building envelope and main structure [12]. The way of distributing the loads is based on the shape and the size of the additional stories. There are two ways of distributing the weight; either by a direct shearing on the exterior walls or by using a load distributing slab.

Direct load bearing method suits the type of roof stacking with additional floors occupying $100 \%$ or less from the roof area [13]. In order to apply this method, a ring beam is built over the existing bearing walls. The ring beams has to main functions; the first is to receive the additional loads from the new extension. The second reason is to increase building's resilience against earthquakes since the majority of the old buildings do not comply with the contemporary regulations of the earthquakes. The new loads are distributed either parallel to the bearing walls or it can be perpendicular as well. The direction of load distribution highly depends on the required architectural design. In one case, both methods could be used at the same time. In this method, it is important for the architectural design to respect the actual design of the existing building and the rhythm of bearing walls, which limits the variety of the prospect designs.

\subsubsection{Indirect load bearing on walls}

Indirect load bearing method comes in favour of providing more flexibility for the architectural design and required spans. In addition, and basically, its suits cases where the roof is not totally stacked, giving the opportunity of providing roof balconies and terraces alike to luxurious penthouses [13]. The process of indirect load bearing requires either a load distributing slab or steel beams system, from which the new loads are distributed to the exterior walls. On one side, additional costs may accompany this method, but on the other side it provides more flexibility.

In this method, additional reinforcements could be added to the existing structure, such as reinforcing soil and foundation, or by adding 
extra beams, columns, slabs or bracings for the walls [11]. The added reinforcement should align with the existing structure, by which added columns should line up with the existing ones and tightly connected to them [38]. Added reinforcement is equivalent to added cost, which requires feasibility study to ensure the profitability of the project. Thus, on the good side, by adding extra reinforcement, it gives the opportunity to add more stories than that when only counting on the shear walls. In addition, it provides more flexibility for the architectural design.

\subsubsection{Construction transition}

Given the process of bearing additional loads, whether through direct or indirect load bearing method, the transition between having an existing roof and adding a new storey remains a complex process that requires a great share of attention. Based on site conditions and the status of the local inhabitants of the existing building, the decisionmaking on the transition method takes place. According to the investigated case studies, two methods were found to be followed based on the roof type: flat or pitched. In projects with flat roof, existing roof is not required to be demolished, nor are the inhabitants needed to be relocate. In this case, additional items on the rooftops (e.g. water tanks) are only required to be taken away and prepare the rooftop to host the new construction according to the most suitable load bearing method. Whereas when having pitched roof, it requires a total demolition of the existing roof. During this process, inhabitants living in the last floor are required to be relocated temporarily. Accordingly, the last floor is needed to be protected from rain and weather conditions, and precast floor slab replaces the old roof construction.

\subsection{Assembly methods}

Assembly method highly depends on urban context and site condition, available tools and technology, and occupants' adaptability. Three main categories are found under the installation methods as shown in Fig. 3, the first is the assembly of 3D modular units, the second is panels

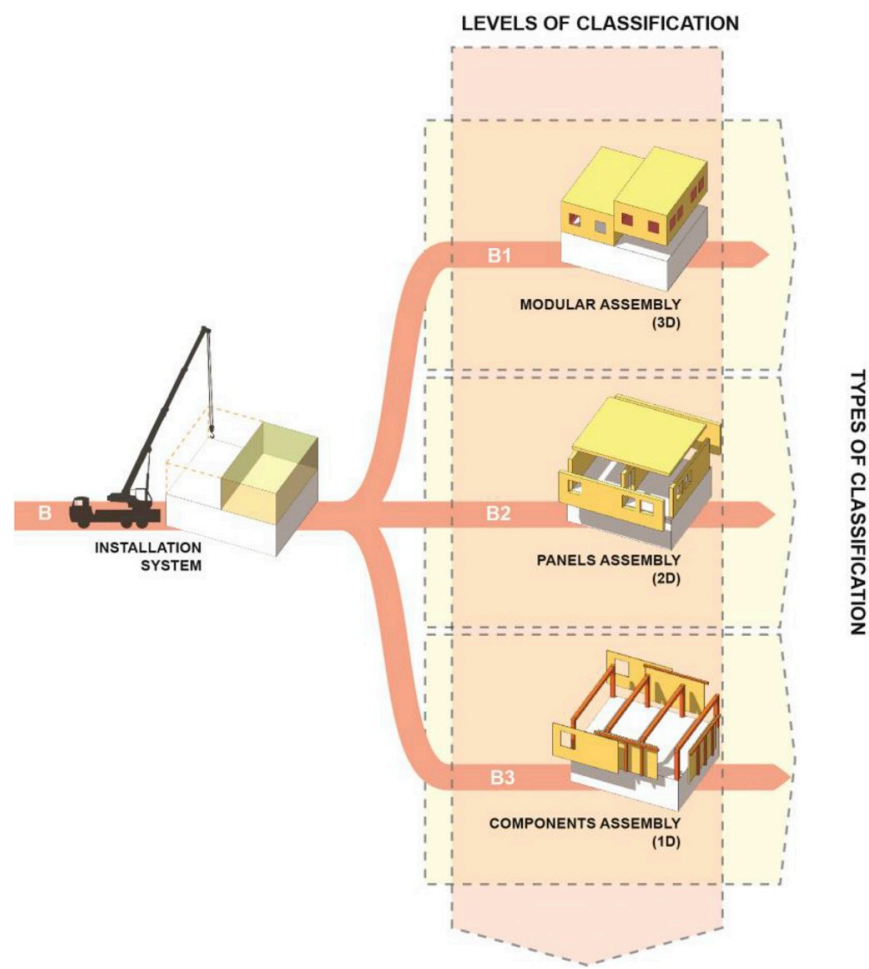

Fig. 3. Classification of roof stacking case studies based on installation methods.
(2D) units' assembly, and the third is components (1D) assembly. However, all methods share the same dependency on prefabrication technology, since it is nearly impossible to carry out a full construction on the rooftop.

\subsubsection{Modular assembly (3D)}

Modular assembly of 3D prefabricated units takes a minimal time, up to three days for installation and assembly, onsite [39], which is considered as a main advantage especially for the cases with high traffic or less working spaces. Moreover, working with 3D modular assembly means that most of the works happens in the factory, where quality is increased as well as the volume needed to be transported. Those units can be in the form of containers, partial or full residential units. They are totally manufactured in the factory, including structural system, walls, floor and ceiling. As a prerequisite, onsite preparations such as clearing the roof and mounting joints should take place before the installation of the units. This method counts on the modularity of the design and modest requirements by prospect inhabitants. However, finishing process including interior and exterior plastering, electricity outlets and sanitation always takes place onsite. Precise measurements for the roof and onsite conditions are prerequisites for a successful assembling procedure and to minimize expected errors for transportation and lifting the elements onto the rooftop. It is recommended to apply optical or digital technologies for cross-checking between the manufacturing tasks in the factory and onsite work and preparations.

\subsubsection{Panels assembly (2D)}

When a project entails higher complexity in the design, the usage of 2D panels is considered a better option. However, less restriction in terms of for occupying the building and its surroundings for longer durations are required [40]. Panels' assembly fit architectural designs with less modularity and big size projects. It is also easier in terms of transportation and lifting. However, this method requires further consideration for the joins design and the assembly techniques between the different architectural elements [11], which means that more work is transferred from the factory to the site, and therefore less quality is achieved compared to 3D modular assembly.

\subsubsection{Components assembly (1D)}

Components in this contexts would refer to beams, columns and frames. Components assembly employ the usage of hybrid systems that includes components together with timber framing and fully modular sanitary compartments [17]. While, the benefits of the onsite total construction and assembling prefabricated elements are achieved, it still consumes more time than other methods. Some cases were recorded, in which a total evacuation of the building form its inhabitants was not required $[11,41]$.

\section{Roof stacking conceptual framework development}

\subsection{Framework overview}

The development of this framework has been adopted from previous literature concerned with decision making in construction in terms of developing a decision-making framework [9,30], criteria [24], or the usage of timber construction [41]. The framework is validated via real case studies and interviews with experts in the field of off-site construction and roof stacking.

The conceptual framework for roof stacking construction is composed of two phases as shown in Fig. 4. Those phases are determined based on the earlier roof stacking construction classification breakdown and onsite practices. In the first phase, a decision is made on the feasibility of the existing building to hold additional weight, in which the choice of the load bearing system takes place. The second phase embraces a multi-disciplinary analysis, on which the choice of the assembly method is based. 


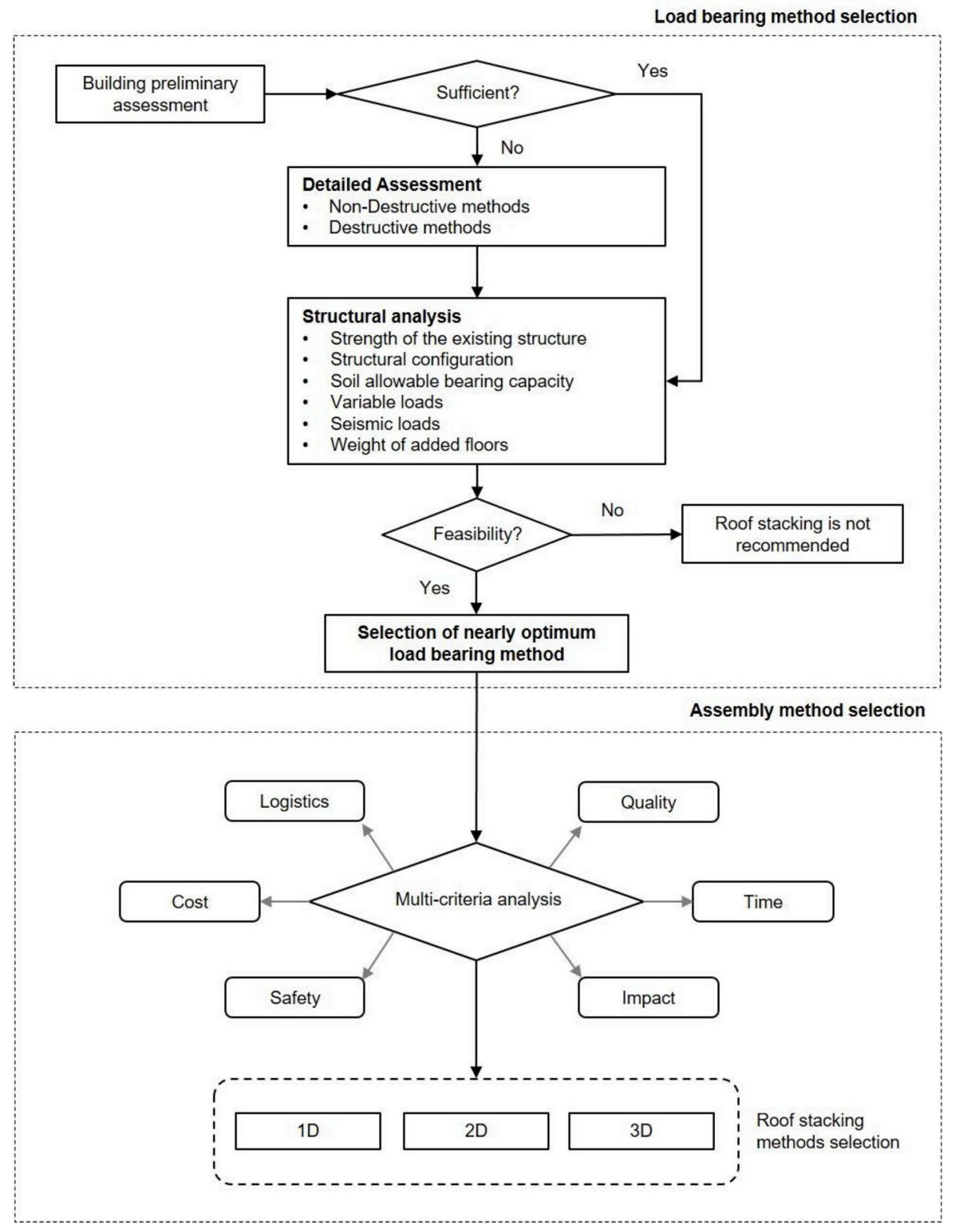

Fig. 4. Decision making framework on roof stacking construction technique.

\subsection{Roof stacking conceptual framework}

\subsubsection{Load bearing method selection}

The first phase of the conceptual framework is concerned with the selection of nearly optimal load bearing method for roof stacking. A preliminary assessment could be identified if there is enough data related to the structural strength and calculations of the existing building. Otherwise, a detailed assessment is required for buildings that have no sufficient documents or old enough to have alterations occurred in their structural behaviour over the time. Detailed assessment could be done by two methods: non-destructive and destructive methods. More details on the assessment of existing buildings are described in the ISO 13822:2010 [42]. A representative workflow has been illustrated as well for the assessment process of the existing buildings [43]. Nondestructive methods include sclerometric, acoustic, radiological, electric and electromagnetic methods [44]. Further building diagnosis have been reviewed in details with identification the most suitable test method according to the aim of investigation [45]. In most cases, destructive methods are combined with non-destructive methods, which includes extraction of concrete cylindrical specimens where characteristic compressive and tensile strength are analysed in the laboratory, or concrete adhesion pull-off test and Rebar exposure, which is used to verify structural drawings or when there is no sufficient information about existing reinforcement. At this stage, specialized civil engineers produce a report that defines the strength of the existing building and decide whether there is a need for additional reinforcement or not.

On this level, each of the strength of the existing building, structural configuration, soil allowable bearing capacity, and the estimated loads of each variable loads, seismic loads, and expected weight of the added floors are measured. By identifying the previous attributes, it is necessary to conduct a feasibility study to determine whether it is feasible to apply roof stacking or not. Feasibility measures on this level are concerned with technical attributes as well as the economic viability of purchasing air right, necessary improvements on the existing building, and if any additional structure or reinforcements are needed. Moreover, there are still inevitable constrains associated with roof stacking projects such as urban regulations, social acceptance, and communication with house owner, which may terminate the analysis process in early stages. All there aspects contributed in the decision-making of carrying 
Table 1

Comparative analysis of different load bearing methods.

Loading on Bearing Walls

\begin{tabular}{|c|c|c|}
\hline & Direct Loading & In-Direct Loading \\
\hline Best Practice & $\begin{array}{l}\text { - Old building with strong bearing walls } \\
\text { - Narrow spans between bearing walls } \\
\text { - Pramiary design requirements } \\
\text { - Less requirement of the number of added floors [46] }\end{array}$ & $\begin{array}{l}\text { - Old building with strong bearing walls } \\
\text { - Large spans between bearing walls } \\
\text { - Advanced design requirements } \\
\text { - Less requirement of the number of added floors } \\
\text { - Higher requirements of safety factor }\end{array}$ \\
\hline Prerequisites & $\begin{array}{l}\text { - Ringbeam that bundles bearing walls \& ready to receive new loads [12] } \\
\text { - Prefabricated frames or } 2 \mathrm{D} \text { elements that vocer the span between existing bearing } \\
\text { walls } \\
\text { - Steel joints in case of perpediculare panels }\end{array}$ & $\begin{array}{l}\text { - Consider the added weight by the new platform } \\
\text { - Connect all bearing walls underneath } \\
\text { - Define the position of the new loads [47] } \\
\text { - Steel beams should comply with fire safety regulation [47] } \\
\text { - Integrating the new reinforcements according to the existing structure } \\
\text { [38] }\end{array}$ \\
\hline Benefits & $\begin{array}{l}\text { - Does not require load redistributing system } \\
\text { - Reduces costs and usage of materials } \\
\text { - Less time is needed for site preparations }\end{array}$ & $\begin{array}{l}\text { - Higher acoustic performance } \\
\text { - Flexibility in distributing load (futur change of function) } \\
\text { - Relatively lightweight distributing system } \\
\text { - Cost less money than the platform } \\
\text { - Potential structural renovation of the existing building }\end{array}$ \\
\hline Drawbacks & $\begin{array}{l}\text { - Less flexibility in terms of interior spaces design } \\
\text { - Less vareity in using building materials and elements (should secure a self- } \\
\text { sustained structural stability) } \\
\text { - Additional weight is only determined by the actual strength of the existing } \\
\text { building }\end{array}$ & $\begin{array}{l}\text { - Additional weight is added without additional space } \\
\text { - Requires more time } \\
\text { - Additional costs } \\
\text { - Less flexibility in distributing loads (no opportunity of changing the } \\
\text { design) } \\
\text { - Requires additional sound insulation [39] } \\
\text { - May contribute in changing the internal or extenral appearance of the } \\
\text { building [11] }\end{array}$ \\
\hline
\end{tabular}

out a roof stacking project or not, which includes regulatory consideration (e.g. terms and conditions for obtaining construction licence, stakeholder involvements, impact on existing inhabitants and surrounding neighbours), as well as feasibility considerations (onsite management associate costs, renovation requirements, etc.).

Table 1 shows a comparative analysis between load bearing systems, on which the best practices, prerequisites, benefits and drawbacks of each systems is explained. However, each of the characteristics of the soil, foundation and the added loads commonly contributes in the decision on roof stacking and load bearing method. This analysis is a cognitive process that takes place in the decision making process. As mentioned previously in the previous section of this research, structural intervention is accustomed to the need of the existing building; either the reinforcement includes soil, foundation, columns, beams, slabs, walls or a combination of some of them, in which each building element has specific method of reinforcement [43]. If the report shows that the building is strong enough to hold additional weight, there would be no need to apply additional reinforcement, instead, one of the load bearing methods are applied directly.

\subsubsection{Assembly method selection}

One the decision on the load bearing system is defined, the phase of selecting the assembly method, and respectively the most adequate building materials, takes place. A multi-disciplinary attributed, in which the decision making process on assembly method takes place, has been developed based on intensive review of literature comprising over 40 publications in the field of building engineering, prefabrication, modularity and off-site construction.

Those indicators have been categorized under the triple bottom lines of sustainability: economic, social, and environmental in some literature $[23,48,49]$. Others have categorized them differently, such as cost, health, architecture, and environment [50,51]. However, in this research, we propose a novel categorization based on the needs oriented towards building on roof tops. This categorization is developed according to an early pilot survey and questionnaire that has been conducted in three languages: English, French, and Dutch, to collect more than 70 responses from experts in the field of roof stacking and off-site construction. Table 2 shows a list of literature with related indicators, on which the multi-disciplinary six factors are based. Those indicators are selected when they at least found in two literature as shown in the table. The six factors are defined as follows: cost, time, safety, quality, environment, and logistics. Cost factor includes labours, building materials, transportation of building materials, maintenance and disposal of construction wastes. Time factor includes the time needed for off-site manufacturing and assembly (for 3D modules), assembly time needed and onsite as well, in addition to the time needed to transport building materials, time intervals between tasks, and the contribution of weather (i.e. weather can cause delays in the project timeline when more tasks are handled onsite, compared to 3D modules that are completely assembled in factory under a complete control of indoor weather). Safety factor includes the safety of workers, the required number of workers on site, and the possibility of losing materials on site. Quality factor includes the quality of the manufactures building components, durability, flexibility of design and construction, integrity of added construction with existing building, constructability, and the aesthetics of the added construction. Environment factor includes the environmental impact (i.e. right to light/air, embodied energy of the building materials, $\mathrm{CO} 2$ emissions, and energy efficiency of the added construction), waste production of onsite materials, noise generation during the construction, pollution produced onsite, water construction and fire resistance of the building materials (e.g. which is also considered as a safety measure). Finally the logistics factor includes dimensional constrains of building materials, availability of a reliable supplier, availability of skilled labours, accessibility of building materials (including cranes access) to working site and on the roof top, site disruption and management.

Thus, some analysis related to the context of the project are needed to be carried out, including design complexity, street width, available cranes or transportation means, traffic regulations, occupancy status of the existent building. Some of these criteria overlap with the load bearing criteria; however, it comes in a later stage since the determination of load bearing method has higher restrictions and priority when it comes to initial feasibility studies. By the end of the second phase, a feasible study could be carried out and determine if it is feasible to apply the project or not as there is a high tendency to abort the project and if it is not feasible. It is also important to mention that the 
Table 2

Multi-disciplinary decision making attributes for assembly method and building materials selection.

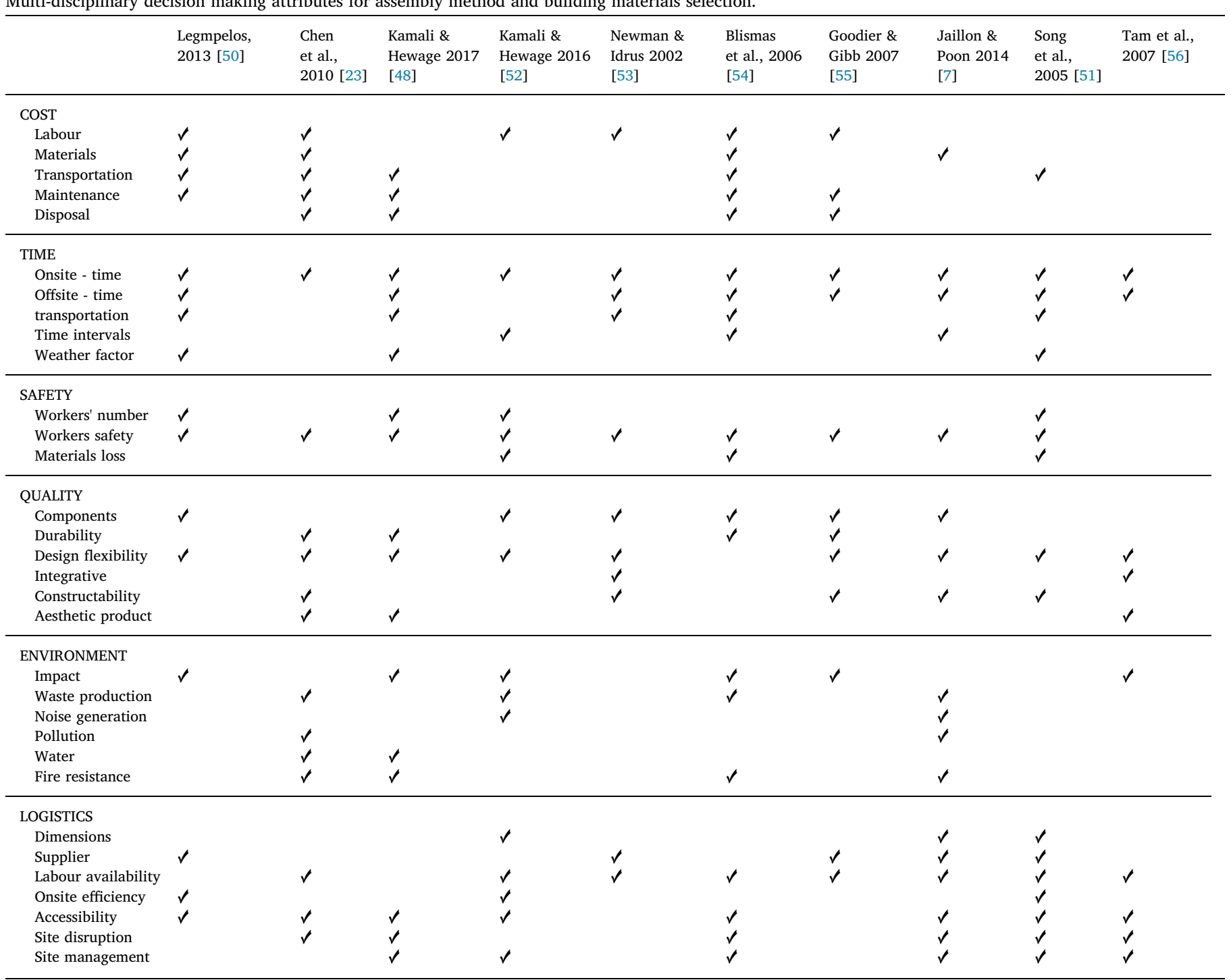

feasibility of the project should include the budget for any needed renovation for the existing building [47].

\subsubsection{Building materials selection}

Throughout the investigations made for roof stacking projects, we found that existing buildings with roof stacking cases were characterized by two different structural systems. Buildings that return back to the nineteenth century and early twentieth century had load bearing constructional system counting on the exterior massive walls, while buildings from late twentieth century had skeleton structure out of reinforced concrete or steel structure [12]. Building materials that have been involved in the process of roof stacking for a structural purpose have been documented throughout the 136 different analysed cases. Even though multiple materials have been listed, it was possible to classify them under 4 main types; reinforced concrete, steel, timber, and composite (a mixture of steel and timber), while the structure of the existing buildings were found in 3 main building materials; Masonry, reinforced concrete and steel.

As shown in Fig. 5, it was found that more than 50\% of the building materials used on buildings with massive structures was made out of lightweight steel, which has a tendency to reflect a modern style contrary to the original style of the existing building. Using timber comes in the second place, while the usage of reinforced concrete comes at the last place. On the other side, timber had more than $50 \%$ of usage for RC buildings, while light weight steel structures comes in the second stage with around $30 \%$ and RC only $14 \%$. Existing buildings with steel skeleton always accommodated extensions made of steel structures or a mixture of steel and timber, however no RC was found to be used over steel structure. The choice of building materials has a direct influence on the total weight per square meter on the original building. Thus, a wise choice of the materials' mixture is important to meet the required aesthetic, structural and energy performance.

It was not possible to list the construction weight of each case; however, some cases were documented. The lightest weight for construction was found to be $80 \mathrm{~kg} / \mathrm{m} 2$ [39], that case claimed to be using timber construction for the structure and building envelope. For other cases using lightweight steel construction materials, the total construction weight ranged between $120 \mathrm{~kg} / \mathrm{m}^{2}$ and $180 \mathrm{~kg} / \mathrm{m}^{2}$ [11], others were listed with $330 \mathrm{~kg} / \mathrm{m}^{2}$ [46,47,57]. Generally, for the best practice, it can be recognized as the lighter the better; however, other considerations are involved to choose the most suitable materials as shown in the previous mentioned criteria for load bearing and installation methods in addition to design necessities, performance requirements, available technology and experience. As a result, the choice of building materials is integrated in the choice of assembly method within those categories. The decision making process of both sections is 


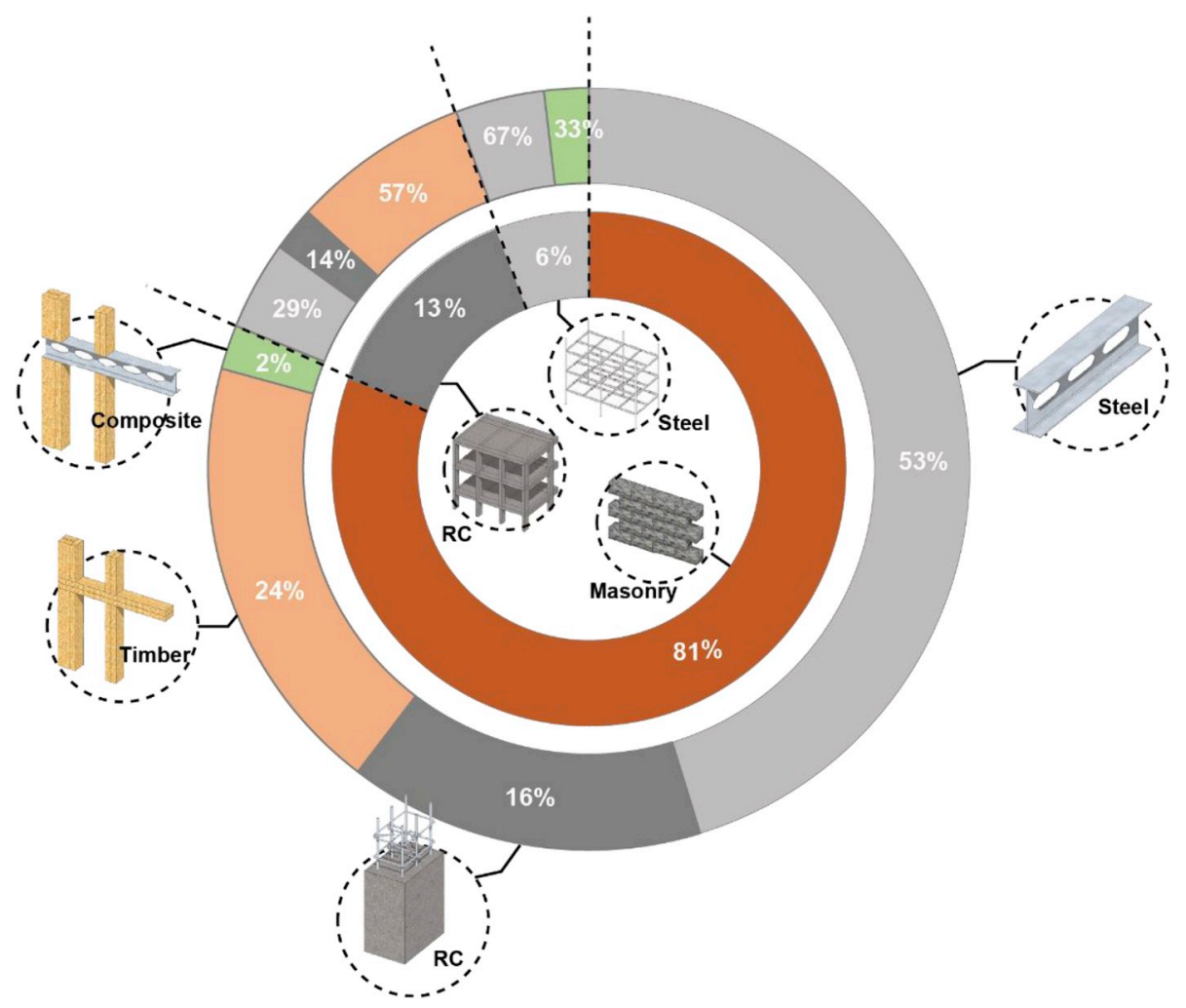

Fig. 5. Building materials usage according to the existing structure.

carried out simultaneously, since they are highly dependent on each other with an overlap in the decision making criteria, such as the weight and maximum span provided by the building material, in addition to the availability of these materials and the manufacturer's capacity. The decision making on building materials includes the weight, maximum span provided by the material, acoustic impedance, fire resistance, thermal performance and life cycle assessment. Thus, by analysing both parts together, a final decision could be made for the type of the intervention and the optimum used building materials in addition to the exact number of additional floors.

\subsubsection{Framework validation loop}

In order to create a validation feedback loop to the conceptual framework development process, up to 10 case studies have been studied thoroughly. However, the interviews do not represent a statistically representative sample, the interview process that started since 2016 reached a saturation level by 2018 . The criteria behind the selection of the case studies are based on the constructional and geographical aspects. First, in terms of the constructional aspect, case studies adopted different roof stacking assembly method: modular, panels, and components assembly. The diversity in the load bearing method has not been considered in the selection process to align with the third aim of the breaking down process (locating the meeting points between the choice of load bearing and assembly method). Second, in term of the geographical aspect, case study are selected from different countries to support the universality in the development of the conceptual framework.

The previously selected case studies have been investigated through semi-structured interviews with the building engineers who were responsible for the design and construction. By adopting the concept of reverse engineering, the process of decision making, on which the selection of roof stacking construction have been made, is broken down. The aim of the interviews is to breakdown the decision making process on roof stacking construction methods selection. Semi-structured interviews have been conducted, face to face, with each of the building engineers. By interacting with every building engineer individually, there was an opportunity to widely explain every project. Every interview lasted between 60 and $90 \mathrm{~min}$, and followed by several emails to provide further information and feedback loop, which was essential in the development of the conceptual framework. The proposed questions were designed to target answers related to the three objectives, previously mentioned, in the breaking down process. Three main points in the breaking down process were essential to approve and validate the framework: (i) defining the criteria on which the choice of load bearing method is based, (ii) evaluating the consideration of the multi-disciplinary attributes when choosing assembly method and building materials, (iii) locating the phase where the feasibility study is conducted, and the meeting point between the choice of load bearing and assembly methods.

\section{Discussion}

This research is based on quantitative and qualitative methods of analysis based on reviewing several projects around Europe, in addition to carrying out interviews with buildings engineers. The results presents a holistic portrayal of settings with an academic and pragmatic focus. The data analysis is thematic with descriptive focus. Thus, the pivotal strength of this research relies in its thorough investigation and review of projects and interviewing different architects with different backgrounds. By reviewing the case studies across Europe we could create a scope and identify patterns on roof stacking construction techniques in the last 20 years. A preempt classification is established for roof stacking construction in terms of building materials, bearing and installation techniques rather than merely a modal one. This classification is a first step towards strengthening the capacity to inform design and structural methods prior to decision making for roof stacking in a systematic and structured way. This research represents as well an inclusive reference for professionals in the field of architecture and building construction with an interest in the field of urban densification and roof stacking using lightweight construction. 
Based on the classification, building materials analysis, and interviews, a decision making framework has been established in this research, which is considered to be the first of its kind that aids the decision making process for roof stacking based. The classification analysis respond to the research questions on the types of applied construction methods for roof stacking, in addition to the criteria and the process of decision making. The decision making framework takes in consideration several aspects; existing building strength capacity, structural configuration, specification of available building material, in which a feasibility study takes place. Finally, the urban context and neighbourhood status that defines the possible installation method and project implementation. We highlight the vital need to increase the density through roof stacking in many European cities, such as Paris, Brussels, Geneva, etc. We are not aware of any previous research that classified or presented clear framework that supports the decision making of roof stacking construction technique. Therefore, we find our work essential to provide a strategically guidance for decision making. However, the availability of information was considered to be a major challenge in this research resulting some limitations. The information gathered from different literatures was not homogeneous, by which the studied sample was not evenly classified. Accordingly, some cases were eliminated from the classification process at certain parts and included in others. It is also important to mention that this research focuses on the constructional methods used for roof stacking without highlighting the operational performance of the case studies.

\section{Conclusion}

A robust classification was established for construction methods used for roof stacking according to our investigation over 136 projects around Europe, reviewing more than 40 manuscripts and interviewing several building engineers with expertise in roof stacking. Further, we present an analysis for the challenges, opportunities and prerequisites for each method that aids the decision making process. The classification represents the main categories of load bearing methods or installation methods, yet it is flexible enough to include additional methods and sub categories, thanks to illustrative scheme that gives the space for further upgrading. The developed classification and framework shows current procedures and contemporary methods roof stacking practices. An intensive review has in related fields has been carried out, followed by several interviews and site visits to assess and validate the developed framework. Currently old infrastructure and residential buildings necessitate retrofitting actions with which adding more floors on the rooftops of existing buildings will enable practical actions to take place.

Thus, this research contributes to the body knowledge in the file of off-site construction generally, and roof stacking specifically. First of all, aligning with UN urban agendas [10] that puts forward compact cities in their priorities to achieve sustainable built environment, this framework is one of the first, if not the first, to propose a decisionmaking framework for roof stacking construction to support a sustainable transition towards urban densification. The structured framework for roof stacking construction takes in consideration multi-disciplinary aspects in the decision-making process, compared to the traditional methods that counts on solely the technical aspects of construction. Lastly, the framework has been developed and validated based on previous research in the file of modular and off-site construction, and through carrying out detailed studies on real case projects and interviews with architects, which represents an added value to the industry sector from the scientific community. The conclusions and contributions of this research could be highlighting as follows:

- A new classification for roof stacking construction methods has been developed in this research. The classification is based on two categories: load bearing and assembly. Under each category, several methods have been identified based on real case projects.
- A multi-disciplinary framework for roof stacking decision making has been developed, where decision-making process takes place on two levels based on the developed classification.

- The decision-making on load baring methods are defined based on the technical attributes of the project, which includes the strength of the existing building, structural configurations, soil and variable loads.

- Whereas six main attributes were identified to affect the decisionmaking on assembly methods, designated as safety, accessibility, cost, time, environmental impact, and quality of construction, which present a unique opportunity to expedite the improvement of the roof stacking construction process.

- Logistics factor includes, but not limited to, the considerations related to loading and transport the roof stacking modules, the space for trucks and auxiliary equipment next of the building work, provision of the large-tonnage crane, collection, in addition to loading and transfer of the demolition waste.

- The technical aspects, as well as the economic viability of those technical aspects (e.g. added structure, purchasing construction license, or the need to first apply improvements on the existing building), plays an important role in the decision-making of the most appropriate load bearing methods.

Future research should build on the developed framework to mathematically identify the nearly optimum percentages of using different roof stacking methods. This should consider references to existing technological capacities and further parameterization of the process to become widely replicated.

\section{Acknowledgment}

This research was funded by a welcome grant provided by Liege University, which are gratefully acknowledged. This publication is part of the research project 2016-2020 entitled: DenCity Prototype: Concepts of Zero Energy Lightweight Construction Households for Urban Densification.

\section{References}

[1] M. Eastman Charles, Sacks Rafael, Relative productivity in the AEC industries in the United States for on-site and off-site activities, J. Constr. Eng. Manag. 134 (2008) 517-526, https://doi.org/10.1061/(ASCE)0733-9364(2008)134:7(517).

[2] J. Egan, Rethinking Construction: the Report of the Construction Task Force to the Deputy Prime Minister, John Prescott, on the Scope for Improving the Quality and Efficiency of UK Construction, Department of the Environment, Transport and the Regions, 1998.

[3] A.A. Yee, Social and environmental benefits of precast concrete technology, PCI J. 46 (2001), https://trid.trb.org/view/692200, Accessed date: 2 May 2018.

[4] A.A. Yee, Structural and economic benefits of precast/prestressed concrete construction, PCI J. 46 (2001), https://trid.trb.org/view/693178, Accessed date: 18 September 2018.

[5] M.R. Hosseini, I. Martek, E.K. Zavadskas, A.A. Aibinu, M. Arashpour, N. Chileshe, Critical evaluation of off-site construction research: a Scientometric analysis, Autom. ConStruct. 87 (2018) 235-247, https://doi.org/10.1016/j.autcon.2017.12. 002 .

[6] C. Goodier, A. Gibb, Future opportunities for offsite in the UK, Constr. Manag. Econ. 25 (2007) 585-595, https://doi.org/10.1080/01446190601071821.

[7] L. Jaillon, C.S. Poon, Life cycle design and prefabrication in buildings: a review and case studies in Hong Kong, Autom. ConStruct. 39 (2014) 195-202, https://doi.org/ 10.1016/j.autcon.2013.09.006.

[8] D. Jato-Espino, E. Castillo-Lopez, J. Rodriguez-Hernandez, J.C. Canteras-Jordana, A review of application of multi-criteria decision making methods in construction, Autom. ConStruct. 45 (2014) 151-162, https://doi.org/10.1016/j.autcon.2014.05. 013.

[9] S. Han, S. Hasan, A. Bouferguene, M. Al-Hussein, J. Kosa, An integrated decision support model for selecting the most feasible crane at heavy construction sites, Autom. ConStruct. 87 (2018) 188-200, https://doi.org/10.1016/j.autcon.2017.12. 009.

[10] United Nations, New Urban Agenda: Statement of Financial Implications (A/71/ 713), (2017) http://www.un.org/en/ga/search/view_doc.asp?symbol=A/RES/71/ 256.

[11] M. Lawson, N. Baddoo, G. Vannier, B. Doering, M. Kuhnhenne, J. Nieminen, P. Beguin, S. Herbin, G. Caroli, I. Adetunji, A. Kozlowski, Review of Roof-Top Extensions Using Light Steel Construction, The Steel Construction Institute (SCI), 
2010, http://www.steel-renovation.org/.

[12] P. Floerke, S. Weiß, L. Stein, M. Wagner, Typologienkatalog gebäudeaufstockungen, bauforumstahl e.V, (2014) https://www.bauforumstahl. de/upload/publications/150301_Typologienkatalog_Onlineausgabe_k.pdf.

[13] K. Tichelmann, K. Groß, Wohnraumpotentiale durch Aufstockungen, Technische Universität Darmstadt, 2016, http://www.bak.de/berufspraxis/bezahlbarerwohnungsbau-fuer-alle/studie-tu-darmstadt-wohnraumpotentiale-durchaufstockung-langfassung.pdf , Accessed date: 30 May 2016.

[14] P. Sharafi, M.N.S. Hadi, L.H. Teh, Optimum column layout design of reinforced concrete frames under wind loading, in: J.M. Caicedo, F.N. Catbas, A. Cunha, V. Racic, P. Reynolds, K. Salyards (Eds.), Top. Dyn. Civ. Struct, vol. 1, Springer, New York, 2012, pp. 327-340.

[15] P. Sharafi, M.N.S. Hadi, H. Teh Lip, Geometric design optimization for dynamic response problems of continuous reinforced concrete beams, J. Comput. Civ. Eng. 28 (2014) 202-209, https://doi.org/10.1061/(ASCE)CP.1943-5487.0000263.

[16] J. Schoenborn, A Case Study Approach to Identifying the Constraints and Barriers to Design Innovation for Modular Construction, Thesis Virginia Tech, 2012, https:// vtechworks.lib.vt.edu/handle/10919/32397 , Accessed date: 18 September 2018.

[17] M. Lawson, R. Ogden, C. Goodier, Design in Modular Construction, CRC Press, 2014.

[18] U. Knaack, S. Chung-Klatte, R. Hasselbach, Prefabricated Systems: Principles of Construction, Walter de Gruyter, 2012.

[19] R.E. Smith, Prefab Architecture: A Guide to Modular Design and Construction, John Wiley \& Sons, 2011.

[20] L. Jaillon, C.S. Poon, Sustainable construction aspects of using prefabrication in dense urban environment: a Hong Kong case study, Constr. Manag. Econ. 26 (2008) 953-966, https://doi.org/10.1080/01446190802259043.

[21] A.N. Baldwin, L.Y. Shen, C.S. Poon, S.A. Austin, I. Wong, Modelling design information to evaluate pre-fabricated and pre-cast design solutions for reducing construction waste in high rise residential buildings, Autom. ConStruct. 17 (2008) 333-341, https://doi.org/10.1016/j.autcon.2007.05.013.

[22] Lawson R. Mark, G. Ogden Ray, Bergin rory, application of modular construction in high-rise buildings, J. Archit. Eng. 18 (2012) 148-154, https://doi.org/10.1061/ (ASCE)AE.1943-5568.0000057.

[23] Y. Chen, G.E. Okudan, D.R. Riley, Sustainable performance criteria for construction method selection in concrete buildings, Autom. ConStruct. 19 (2010) 235-244, https://doi.org/10.1016/j.autcon.2009.10.004.

[24] Y. Chen, G.E. Okudan, D.R. Riley, Decision support for construction method selection in concrete buildings: prefabrication adoption and optimization, Autom ConStruct. 19 (2010) 665-675, https://doi.org/10.1016/j.autcon.2010.02.011.

[25] P.O. Akadiri, P.O. Olomolaiye, E.A. Chinyio, Multi-criteria evaluation model for the selection of sustainable materials for building projects, Autom. ConStruct. 30 (2013) 113-125, https://doi.org/10.1016/j.autcon.2012.10.004.

[26] J. Fernandez-Ceniceros, R. Fernandez-Martinez, E. Fraile-Garcia, F.J. Martinez-dePison, Decision support model for one-way floor slab design: a sustainable approach, Autom. ConStruct. 35 (2013) 460-470, https://doi.org/10.1016/j.autcon. 2013.06.002.

[27] P. Jensen, T. Olofsson, H. Johnsson, Configuration through the parameterization of building components, Autom. ConStruct. 23 (2012) 1-8, https://doi.org/10.1016/j. autcon.2011.11.016.

[28] Z. Yuan, C. Sun, Y. Wang, Design for Manufacture and Assembly-oriented parametric design of prefabricated buildings, Autom. ConStruct. 88 (2018) 13-22, https://doi.org/10.1016/j.autcon.2017.12.021.

[29] H.M. Said, T. Chalasani, S. Logan, Exterior prefabricated panelized walls platform optimization, Autom. ConStruct. 76 (2017) 1-13, https://doi.org/10.1016/j. autcon.2017.01.002.

[30] T. Salama, A. Salah, O. Moselhi, M. Al-Hussein, Near optimum selection of module configuration for efficient modular construction, Autom. ConStruct. 83 (2017) 316-329, https://doi.org/10.1016/j.autcon.2017.03.008.

[31] P. Sharafi, B. Samali, H. Ronagh, M. Ghodrat, Automated spatial design of multistory modular buildings using a unified matrix method, Autom. ConStruct. 82 (2017) 31-42, https://doi.org/10.1016/j. autcon.2017.06.025.

[32] P. Sharafi, M. Mortazavi, B. Samali, H. Ronagh, Interlocking system for enhancing the integrity of multi-storey modular buildings, Autom. ConStruct. 85 (2018) 263-272, https://doi.org/10.1016/j.autcon.2017.10.023.

[33] M. Amer, A. Mustafa, J. Teller, S. Attia, S. Reiter, A methodology to determine the potential of urban densification through roof stacking, Sustain. Cities Soc. 35 (2017) 677-691, https://doi.org/10.1016/j.scs.2017.09.021.

[34] M. Amer, S. Reiter, S. Attia, Urban densification through roof stacking: case study,
Eur. Netw. Hous. Res. ENHR Annu. Conf. 2018, Uppsala University, Uppsala, Sweden, 2018, https://orbi.uliege.be/handle/2268/226538 , Accessed date: 16 July 2018.

[35] K. Nilsson, T. Nielsen, C. Aalbers, S. Bell, Strategies for Sustainable Urban Development and Urban-Rural Linkages, (2014).

[36] A.-F. Marique, S. Reiter, Retrofitting the suburbs: insulation, density, urban form and location, Environ. Manag. Sustain. Dev. 3 (2014), http://orbi.ulg.ac.be/ handle/2268/173790, Accessed date: 2 May 2016.

[37] X. Wang, P.E.D. Love, M.J. Kim, C.-S. Park, C.-P. Sing, L. Hou, A conceptual framework for integrating building information modeling with augmented reality, Autom. ConStruct. 34 (2013) 37-44, https://doi.org/10.1016/j.autcon.2012.10. 012.

[38] M. Lawson, N. Baddoo, G. Vannier, B. Doering, M. Kuhnhenne, J. Nieminen, P. Beguin, S. Herbin, G. Caroli, I. Adetunji, A. Kozlowski, WP 5.3.8. High quality roof - top extension in boulogne, the steel construction institute (SCI), (2010) http://www.steel-renovation.org/.

[39] J. Artés, La casa por el tejado, (2016) http://www.lacasaporeltejado.eu/en/, Accessed date: 6 June 2016.

[40] G. Reinberg, Passivhaussanierung und nachverdichtung, Kierling, Proc. Okosan15 Int. Konf. Hochwertige Sanier. Nachverdichtung Mit Holzbausystemen, AEE Institut für Nachhaltige Technologien, Gleisdorf, Graz, Austria, 2015.

[41] G. Ruellan, S. Attia, Wood, the materials of the tomorrow retrofits, Proc. Okosan15 Int. Konf. Hochwertige Sanier. Nachverdichtung Mit Holzbausystemen, AEE Institut für Nachhaltige Technologien, Gleisdorf, Graz, Austria, 2015.

[42] ISO 13822, Bases for design of structures. Assessment of existing structures, (2010) http://www.iso.org/iso/catalogue_detail? csnumber $=46556$.

[43] M. Papageorgiou, Optimal Vertical Extension: a study on costs and environmental impact for structural engineers, TU Delft, (2016) https://repository.tudelft.nl/ islandora/object/uuid:59fb6d8d-58ab-494d-9fe3-ef0931244fc6? collection = education , Accessed date: 27 May 2017.

[44] L. Runkiewicz, Application of non-destructive testing methods to assess properties of construction materials in building diagnostics, Archit. Civ. Eng. Environ. 2 (2009) 79-86.

[45] C. Maierhofer, H.-W. Reinhardt, G. Dobmann, Non-Destructive Evaluation of Reinforced Concrete Structures: Non-destructive Testing Methods, Elsevier, 2010.

[46] J. Artes, G. Wadel, N. Marti, Vertical extension and improving of existing buildings, Open Constr. Build. Technol. J. 11 (2017), https://doi.org/10.2174/ 1874836801711010083.

[47] M. Amer, S. Attia, ROOF STACKING: learned lessons from architects, SBD Lab, 2017, http://orbi.ulg.ac.be/handle/2268/210472, Accessed date: 26 May 2017.

[48] M. Kamali, K. Hewage, Development of performance criteria for sustainability evaluation of modular versus conventional construction methods, J. Clean. Prod. 142 (2017) 3592-3606, https://doi.org/10.1016/j.jclepro.2016.10.108.

[49] M. Amer, S. Attia, Identification of sustainable criteria for decision-making on roof stacking construction method, Sustain. Cities Soc. 47 (2019) 101456, https://doi. org $/ 10.1016 /$ j.scs.2019.101456.

[50] N. Legmpelos, On-site construction versus prefabrication, thesis, Massachusetts institute of technology, (2013) http://dspace.mit.edu/handle/1721.1/82714 Accessed date: 18 October 2017

[51] Jongchul Song, R. Fagerlund Walter, T. Haas Carl, B. Tatum Clyde, A. Vanegas Jorge, considering prework on industrial projects, J. Constr. Eng. Manag. 131 (2005) 723-733, https://doi.org/10.1061/(ASCE)0733-9364(2005)131:6(723).

[52] M. Kamali, K. Hewage, Life cycle performance of modular buildings: a critical review, Renew. Sustain. Energy Rev. 62 (2016) 1171-1183, https://doi.org/10.1016/ j.rser.2016.05.031.

[53] A.B. Idrus, J.B. Newman, Construction related factors influencing the choice of concrete floor systems, Constr. Manag. Econ. 20 (2002) 13-19, https://doi.org/10 1080/01446190110101218.

[54] N. Blismas, C. Pasquire, A. Gibb, Benefit evaluation for off-site production in construction, Constr. Manag. Econ. 24 (2006) 121-130, https://doi.org/10.1080/ 01446190500184444.

[55] C. Goodier, A. Gibb, Future opportunities for offsite in the UK, Constr. Manag. Econ. 25 (2007) 585-595, https://doi.org/10.1080/01446190601071821.

[56] V.W.Y. Tam, C.M. Tam, S.X. Zeng, W.C.Y. Ng, Towards adoption of prefabrication in construction, Build. Environ. 42 (2007) 3642-3654, https://doi.org/10.1016/j. buildenv.2006.10.003.

[57] J. Artes, L. Volpi, G. Wadel, N. Marti, Senda, progressive environmental quality system for rooftop flats, Int. Conf. Sustain. Hous. Plan. Manag. Usability, Green Lines Institute for Sustainable Development, Porto, Portugal, 2016. 